\title{
MATERIALS FOR SONOTRODE TOOLS
}

\author{
Š. Emmer ${ }^{1}$, J. Kováčik ${ }^{2}$ and S. Mrkvováa ${ }^{3}$ \\ ${ }^{1}$ Institute of Technologies and Materials, Faculty of Mechanical Engineering, IVMA STU, Slovak \\ University of Technology, Pionierska 15, 83102 Bratislava, Slovak Republic, \\ stefan.emmer@stuba.sk \\ ${ }^{2}$ Institute of Materials and Machine Mechanics, Slovak Academy of Sciences, Račianska 75, 831 \\ 02 Bratislava, Slovak Republic, ummsjk@savba.sk \\ ${ }^{3}$ Slovak University of Technology in Bratislava, Faculty of Mechanical Engineering, Institute of \\ Technologies and Materials, Pionierska 15, 83102 Bratislava,simona.mrkvova@stuba.sk
}

Keywords: Ultrasonic, sonotrode materials, tool materials, sonotrode tool materials

\begin{abstract}
The investigation of appropriate steels for sonotrode tool applications was performed. In this not only good sonotrode properties (good transmission of ultrasonic energy, resistance to gigacycle fatigue) are required, but also the material ought to meet tool properties (high hardness and wear resistance). The investigation was focused on tool steels, which are cheaper than the currently best sonotrode tool material FerroTitanit cermet, and better than usual sonotrode materials AW 7075 aluminium alloy and titanium alloy Ti6Al4V. The suitability of steels for this purpose was evaluated by measuring the ultrasound energy transmission at frequency of $30 \mathrm{kHz}$.
\end{abstract}

\section{INTRODUCTION}

Today as sonotrode tools FerroTitanit cermet goods are often used [1,2]. This solution is expensive and moreover possesses difficult machining to required shape. Therefore cheaper good sonotrode materials AW 7075 aluminium alloy and titanium alloy Ti6Al4V with simpler machining are often used. The problem with these materials is that due to their mechanical properties such as medium hardness and low wear resistance they are not usable as sonotrode tools. Therefore the investigation of tool steels for sonotrode tool applications is the main aim of the present paper.

\section{EXPERIMENT}

The samples were prepared from various tool steels and FerroTitanit cermet (for comparison) by machining for ultrasonic testing (see Fig. 1) according to ultrasonic needs. Therefore, the length of samples L was determined on the basis of the properties of steel and the requirements of good propagation of ultrasound at a frequency of $30 \mathrm{kHz}$.

The appropriateness of steels for this purpose was evaluated by measuring of the lowest necessary input power for the ultrasound energy transmission at a frequency of $30 \mathrm{kHz}$. Today in ultrasound praxis there are used lower input powers for the ultrasound energy transmission at a frequency of $20 \mathrm{kHz}$. The second criterion was evaluation of achieved maximal displacement of tool at constant frequency. 

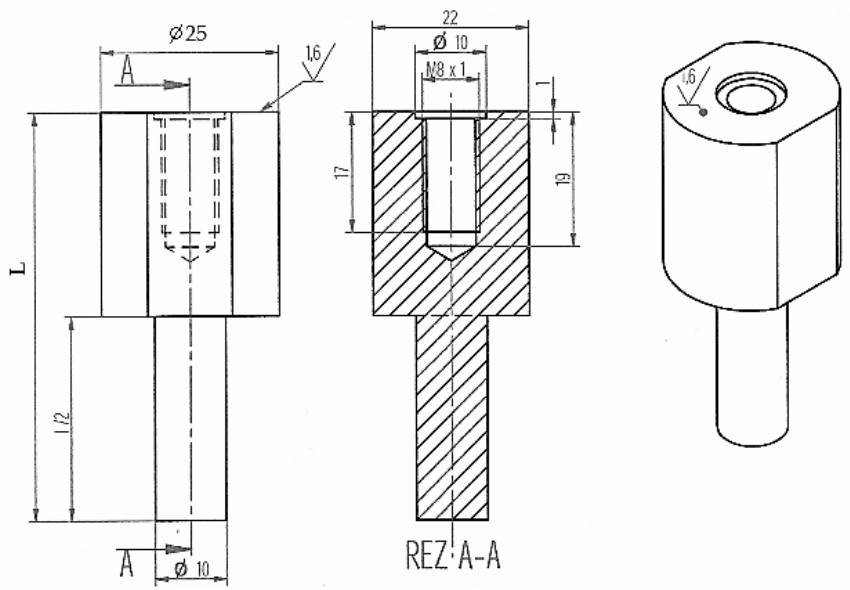

Figure 1:Experimental samples used for ultrasonic testing and their geometry.

The experimental set-up is on Fig. 2. The device enables to vary the power source voltage in the range of $50-250 \mathrm{~V}$. It can measure the deflection of the sample using a micrometer(item 6) and also input power into the sample (item 5). The tests were conducted with and also without the booster (item 4). During the test 300W transducer was used (item 3). The experiments were carried out on the samples before and after heat treatment/thermo-chemical treatment. Tests prior to treatment were realized with the booster to reduce the maximum displacement. As was mentioned above the criteria for comparison of samples were the maximum displacementand the minimum input power at a constant frequency of $30 \mathrm{kHz}$.

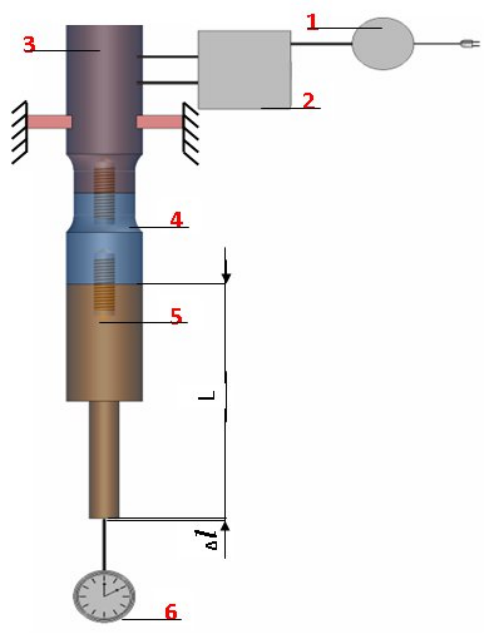

Figure 2:Experimental set-up for ultrasonic testing: 1- measurement of power input, 2 - power source, 3 - piezoelectric transducer, 4 - booster, 5 - sample, 6 - micrometer.

The tool steels that are thermally treated or thermo-chemically treated were investigated in this study. Heat treatment of the samples was carried out in a vacuum furnace or under protective 
atmosphere. Individual steel requires different parameters of heat treatment (it was performed according to the parameters defined by manufacturer or by the material definitions). Thermochemical heat treatment was carried out in continuous furnaces with low and higher chemical potential of carbon for enhanced diffusion of carbon into the steel surface.

\section{RESULTS AND DISCUSSION}

Generally, all samples had a higher displacement and less input power in the state after heat treatment than before heat treatment. Basically, all tested steels are suitable for the manufacture of tools for ultrasonic machining. The best conditions showed heat-treated steel CPM 10V [3], because that was the only one that can be tested at the maximum voltage without breaking the sample and reached also highest amplitude of displacement, which is the most advantageous for the production of ultrasonic tools. This is probably due to the hyperfine structure of that of steel, which was prepared by powder metallurgy methods (see Fig. 3). High performance steel CPM $10 \mathrm{~V}$ with increased content of vanadium and carbon can be air hardened. The combination of its toughness, wear resistance and cutting edge stability predestination it to replace tool steel which during the cold working, are prone to breaking or chipping. Substitution of these tool steels by CPM 10V decreases the cost of tools repair. This steel is mainly used for cutting and stamping tools, precision cutting toolsand punches for punching where is required a high toughness of steel. Chemical composition of CPM $10 \mathrm{~V}$ steel is in Table 1.

Table 1: Chemical composition of CPM 10V steel [wt. \%].

\begin{tabular}{|l|l|l|l|l|l|l|}
\hline $\mathbf{C}$ & $\mathbf{M n}$ & $\mathbf{C r}$ & $\mathbf{V}$ & $\mathbf{S i}$ & $\mathbf{N i}$ & $\mathbf{P}$ \\
\hline $2.4 \%$ & $0.5 \%$ & $5.25 \%$ & $9.75 \%$ & $0.9 \%$ & $1.3 \%$ & $0.025 \%$ \\
\hline
\end{tabular}

The CPM 10V tool steel was heat treated as follows: for the best combination of toughness and wear resistance hardening at $1120{ }^{\circ} \mathrm{C}$ takes place, soaking time $30-45$ minutes (all in protective atmosphere), and then it was air quenched and tempered 3 times at $550 \mathrm{C}$.

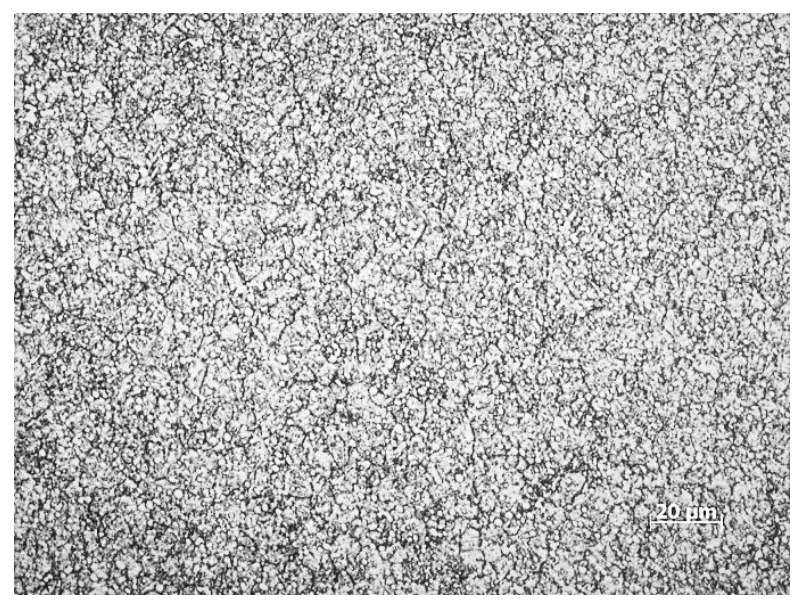

Figure 3: Microstructure of CPM 10V steel after thermal heat treatment with fine and homogeneously distributed VC carbides in steel matrix (64 HRC). 
Also in the case of thermo-chemical heat treatment of 16MnCr5V (ASTM 5115/5117) steel was found the positive effect on ultrasonic characteristics of the samples. Carburization in an atmosphere with higher carbon chemical potential has more positive effect on increasing of the sample displacement when compared to lower-carbon chemical potential.These samples had the same power as the sample carburized at low-carbon chemical potential, but had a slightly larger displacement. However, the obtained results are lower compared to the results achieved by heattreated high alloy vanadium steel CPM 10V (see Figs. 6-7). The steel $16 \mathrm{MnCr} 5$ is frequently used for steel transmission parts and other parts of mechanical engineering, which are hardened after machining. Chemical composition of $16 \mathrm{MnCr} 5 \mathrm{~V}$ (ASTM 5115/5117) steel is in Table 2 and microstructure after treatment on Fig. 4.

Table 2: Chemical composition of 16MnCr5V (ASTM 5115/5117) steel [wt. \%].

\begin{tabular}{|l|l|l|l|l|l|}
\hline $\mathbf{C}$ & $\mathbf{M n}$ & $\mathbf{C r}$ & $\mathbf{S i}$ & $\mathbf{S}$ & $\mathbf{P}$ \\
\hline $0.19 \%$ & $1.3 \%$ & $1.1 \%$ & $0.4 \%$ & $0.035 \%$ & $0.035 \%$ \\
\hline
\end{tabular}

The $16 \mathrm{MnCr} 5 \mathrm{~V}$ steel was thermo-chemically treated as follows: carburization at $820^{\circ} \mathrm{C}$ (carbon potential $0.8 \mathrm{wt} . \%$ ) and at $960^{\circ} \mathrm{C}$ (carbon potential $1.2 \mathrm{wt} . \%$ ) followed by diffusion at $960^{\circ} \mathrm{C}$ and hardening at $820^{\circ} \mathrm{C}$ (carbon potential $0.7 \mathrm{wt} . \%$ for both steps), all steps last together 250 minutes. The last operation was tempering at $150^{\circ} \mathrm{C}$ for 105 minutes.

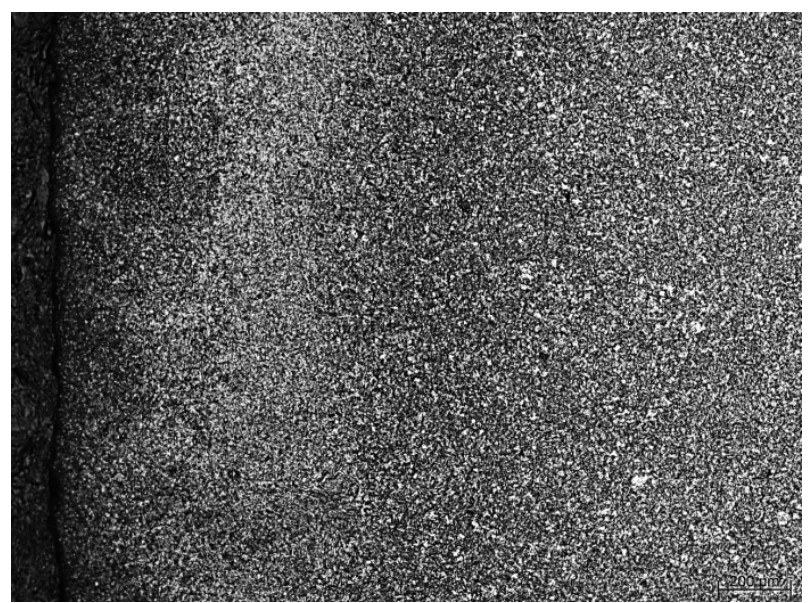

Figure 4: Microstructure of $16 \mathrm{MnCr} 5$ steel after thermo-chemical treatment in an atmosphere with higher chemical potential of carbon.

FerroTitanit WFN [4] is a trademark of metal-ceramic tool material (cermet). The matrix is created by $\mathrm{Cr}-\mathrm{Mo}$ steel that can be heat treated. In the matrix is present $33 \mathrm{wt} \%$ of TiC carbide which is 45 vol. \% of carbide in steel matrix (see Fig. 5). This material is usually used as a tool material for operations such as cutting and forming and predominantly for instruments and components to be highly resistant to wear. It's chemical composition is in Table 3.In this case the heat treatment was realized in vacuum furnace. The heating up to hardening temperature $\left(1080^{\circ} \mathrm{C}\right)$ was realized using 3 preheating stages $400^{\circ} \mathrm{C}, 650^{\circ} \mathrm{C}$ and $850^{\circ} \mathrm{C}$. Quenching to $50^{\circ} \mathrm{C}$ was in argon atmosphere at pressure of $0.1 \mathrm{MPa}$. It was immediately followed by tempering in the region of secondary 
hardness maxima at $480^{\circ} \mathrm{C}$ with dwelling on the temperature for 2.5 hour. Achieved final hardness after heat treatment was $68 \mathrm{HRC}$.

Table 3:Chemical composition of FerroTitanit WFN [wt. \%].

\begin{tabular}{|l|l|l|l|l|}
\hline $\mathbf{C}$ & Mo & $\mathbf{C r}$ & $\mathbf{T i C}$ & $\mathbf{F e}$ \\
\hline $0.75 \%$ & $3.0 \%$ & $13.5 \%$ & $33.0 \%$ & balanced \\
\hline
\end{tabular}

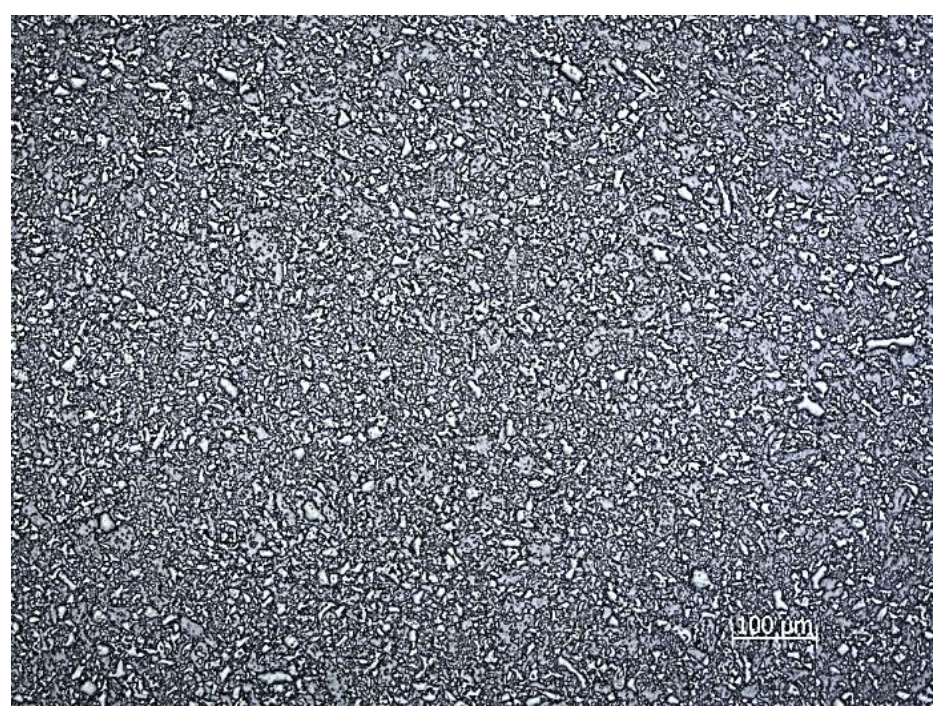

Figure 5: FerroTitanit WFN - martensitic structure with TiC carbides (68 HRC)

FerroTitanit WFN proved the best input powers when compared to the tested steels. It had the smallest power input at given voltage (minimum power required for conducting ultrasonic energy). On the other hand measured displacements were smallest at given input voltage (see Figs. 6-7). Also the main disadvantage in this case was its difficult machinability.

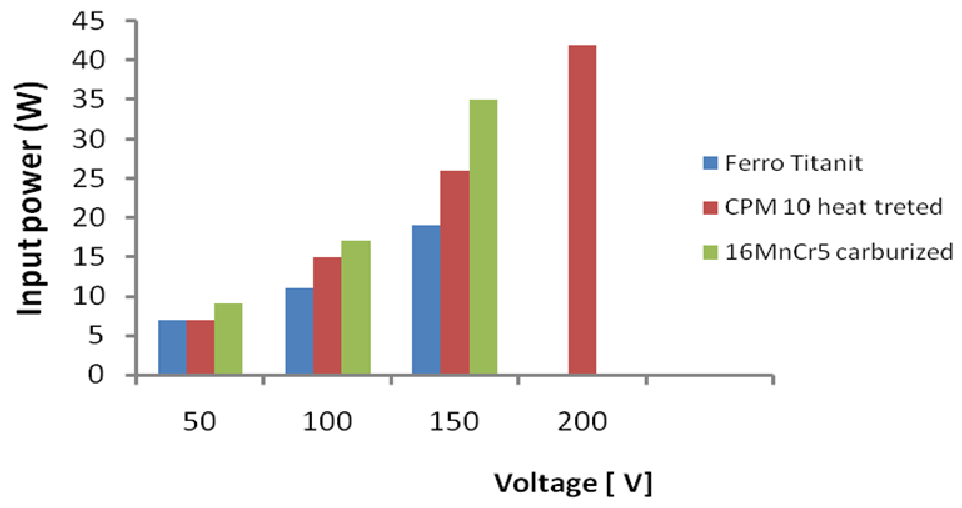

Figure 6:Comparison of input power into tools made from various steels at different voltage: FerroTitanit cermet, CPM $10 \mathrm{~V}$ tool steel after heat treatment and $16 \mathrm{MnCr} 5 \mathrm{~V}$ steel thermochemically treated. 


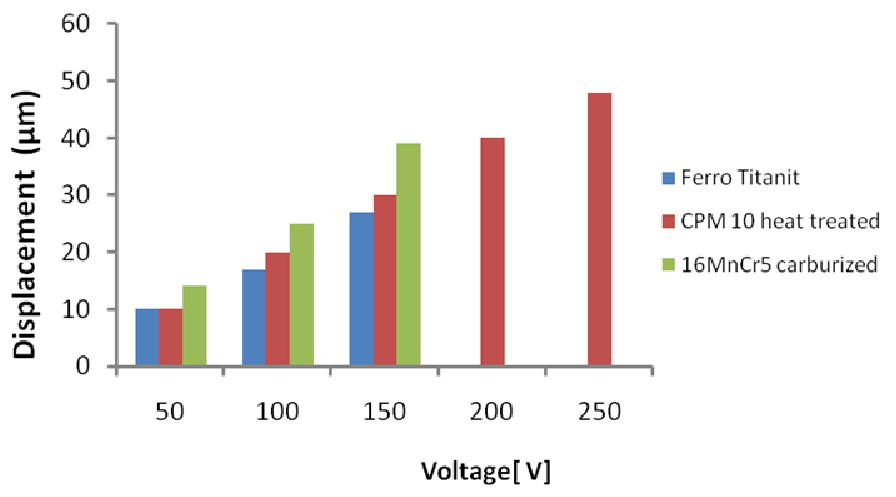

Figure 7:Comparison of tip displacement of tools made from various steels at different voltage: FerroTitanit cermet, CPM 10V tool steel after heat treatment and $16 \mathrm{MnCr} 5 \mathrm{~V}$ thermo- chemically treated

\section{CONCLUSIONS}

It can be concluded that it was experimentally observed and confirmed that the certain heat treated tool steels can be successfully used as sonotrode tool materials. It was found that the heat treatment has a positive effect on the ultrasonic characteristics of steels. All samples had greater displacement and less power consumption in the state after heat treatment as prior to heat treatment. When testing heat-treated samples, the best results were achieved for high vanadium alloy steel CPM 10V prepared by powder metallurgy. Measurement of the amplitude of sample oscillations without breaking was able up to the voltage of $200 \mathrm{~V}$ for this steel. The CPM $10 \mathrm{~V}$ sample was damaged at $250 \mathrm{~V}$. This steel has exceptional resistance to wear due to fine and uniformly distributed VC phase in the steel matrix after heat treatment. However input power in compare to FerroTitanit cermet was higher. In the case of thermo-chemically treated $16 \mathrm{MnCr} 5$ steel the good results were also achieved. However, the results are lower in comparison to the results which were achieved in case of vanadium alloy steel CPM 10V.

\section{ACKNOWLEDGMENT}

Authors thank to Slovak Grant Agency - VEGA grants No. 1/0114/10, No. 1/0189/12 and APVV 20-057805, APVV VMSP-II-0009-09 for funding of this work.

\section{REFERENCES}

[1] Lucas, M., Petzing, J.N., Cardoni, A., Smith, L.J., Design and characterisation of ultrasonic cutting tools, CIRP Annals - Manufacturing Technology, Vol. 50, 2001, pp. $149-152$

[2] Lucas M., MacBeath, A., McCulloch, E., Cardoni, A., A finite element model for ultrasonic cutting, Ultrasonics, Vol. 44, 2006, pp. e503-e5

[3] Haswell et al., Powder-metallurgy steel article with high vanadium-carbide content, 1981, US Patent, 4,249,945 
SCIENTIFIC PROCEEDINGS 2013, Faculty of Mechanical Engineering, STU in Bratislava Vol. 21, 2013, pp. 44-50, DOI: 10.2478/stu-2013-0008

[4] Ferro-Titanit ${ }^{\circledR}$ Powder-metallurgical carbide alloyed materials, DEUTSCHE EDELSTAHLWERKE GMBH, Krefeld, Germany, 2007. 